\title{
Protective effects of two Astragalus species on ulcerative colitis in rats
}

\author{
Gamal A Soliman ${ }^{1,2}$, Gamal A Gabr ${ }^{1,3}$, Fahad I Al-Saikhan ${ }^{4}$, Mohd Nazam \\ Ansari $^{1 *}$, Tajdar H Khan ${ }^{1}$, Majid A Ganaie ${ }^{1}$, Saeedan S Abdulaziz ${ }^{1}$ and Özgen \\ Alankuş-Çalışkan ${ }^{5}$ \\ ${ }^{1}$ Department of Pharmacology, College of Pharmacy, Prince Sattam bin Abdulaziz University, Al-Kharj, Kingdom of Saudi \\ Arabia, ${ }^{2}$ Department of Pharmacology, College of Veterinary Medicine, Cairo University, ${ }^{3}$ Agricultural Genetic Engineering \\ Research Institute, Agric. Res. Center, Giza, Egypt, ${ }^{4}$ Department of Clinical Pharmacy, College of Pharmacy, Prince Sattam bin \\ Abdulaziz University, Al-Kharj, Kingdom of Saudi Arabia, ${ }^{5}$ Department of Chemistry, Faculty of Science, Ege University, \\ Bornova, Izmir, 35100, Turkey
}

*For correspondence: Email: m.ansari@psau.edu.sa; Tel: +966-11-5886037

\begin{abstract}
Purpose: To investigate the anti-inflammatory activities of root extracts of Astragalus gummifera and Astragalus kurdicus, as well as their protective effects against acetic acid-induced ulcerative colitis (UC) in rats.

Methods: The roots of both species were shade-dried, pulverized to fine powder and extracted with 80 $\%$ ethanol. The extracts were lyophilized using freeze-dryer, and their anti-inflammatory effects were evaluated in rats by carrageenan-induced paw edema. In UC study, the extracts, at doses of 200 and $400 \mathrm{mg} / \mathrm{kg}$, were given orally to rats for 5 days, with the last dose given $2 \mathrm{~h}$ prior to colitis induction. Histopathological studies were carried out on the colon tissues. Dexamethasone (DEX) was used as standard anti-inflammatory drug.

Results: A. gummifera (400 mg/kg) and A. kurdicus (200 and $400 \mathrm{mg} / \mathrm{kg}$ ) significantly reduced carrageenan-induced edema, offered protection against UC and arrested UC-induced increases in myeloperoxidase (MPO) activity. Histological examination of colon sections also revealed evidence of extract-induced protection from UC.

Conclusion: These results suggest that $A$. gummifera and $A$. kurdicus root extracts have promising potential as sources of anti-inflammatory agents which may be useful in the treatment of UC.
\end{abstract}

Keywords: Colon ulcer, Astragalus gummifera, Astragalus. kurdicus Inflammation, Myeloperoxidase, Ulcer index

Tropical Journal of Pharmaceutical Research is indexed by Science Citation Index (SciSearch), Scopus, International Pharmaceutical Abstract, Chemical Abstracts, Embase, Index Copernicus, EBSCO, African Index Medicus, JournalSeek, Journal Citation Reports/Science Edition, Directory of Open Access Journals (DOAJ), African Journal Online, Bioline International, Open-J-Gate and Pharmacy Abstracts

\section{INTRODUCTION}

UC is a chronic gastro-intestinal disease characterized by inflammatory changes and mucosal tissue injury. The pathogenesis of UC is still not clear, but some causative factors have been suggested. These include environmental, genetic and microbial and immuno-regulatory factors [1]. The principal drugs used for management of UC are corticosteroids, 5aminosalicylate, azathioprine, methotrexate, cyclosporine, vancomycin, ciprofloxacin and metronidazole [2]. Although these medications have good treatment outcomes, they produce adverse effects which have reduced their clinical applications. Despite lots of research efforts on this disease, no specific treatments have been developed so far [3]. It is known that plant 
products have less toxic effects than synthetic ones and are good sources of novel therapeutic agents [4]. Thus in recent years, attention has considerably shifted to use herbal medicine in treating UC.

Astragalus which belongs to the family Fabaceae, consists of 380 species and is the largest genus of flowering plants in the flora of Turkey [5]. Different species of Astragalus genus are reported to possess numerous pharmacological activities such as immunestimulatory effects [6], anti-bacterial and antiviral properties; ability to promote nucleic acid synthesis in the liver, hepato-protective activities, anti-inflammatory activities, and cardiovascular effects such as hypotensive and vasodilatory properties $[7,8]$.

Astragalus has also been used in the treatment of diabetes mellitus, nephritis, leukemia and uterine cancer [9]. It is usually used as topical therapy for relief of rheumatoid arthritis, toothache, and neck pain, or orally for treating stomach pain [10]. The active constituents of Astragalus plants include flavonoids, saponins, polysaccharides, anthraquinones, alkaloids, $\beta$ sitosterol and amino acids. Flavonoids have marked antioxidant properties and show protective activities against pathological changes in liver, lung, kidney and heart [11,12]. Astragalus polysaccharides have been shown to induce endogenous interferon production in animals and humans, and to potentiate the actions of interferon in viral infections [13].

The objective of the present investigation was to evaluate the anti-inflammatory activities of $A$. gummifera and $A$. kurdicus root extracts and their potential to protect against UC in an experimental model of acetic acid-induced UC in rats.

\section{EXPERIMENTAL}

\section{Chemicals}

Carrageenan and DEX were procured from Sigma-Aldrich (St Louis, MO, USA). Ethanol was purchased from Scharlab, S.L. Spain. Other chemicals were of analytical grade.

\section{Plant material}

Astragalus gummifera Labill was collected along Elazig-Hazargolu Road, East Anatolia, Turkey, in June 2010. The plant was authenticated by Prof Zeki Aytac, of Gazi University, Faculty of Science and Art, Department of Biology, Ankara, Turkey. A voucher specimen (no. HUEF 00-23) was deposited in the Herbarium of the Pharmaceutical Botany Department, Pharmacy College, Hacettepe University, Ankara, Turkey. Astragalus kurdicus Boiss. var. kurdicus was collected from Van: Gevaş, Alacabük mountain (southern slopes, 2850m altitude), East Anatolia, Turkey in June 2010. It was identified by Associate Professor Dr Fevzi ÖzgökCe, Yüzüncü Yıl University, Science and Art College, Department of Biology, Van, Turkey. A voucher specimen (no: VANF 13805) was deposited in the Herbarium of Yüzüncü Yıl University, Van, Turkey.

\section{Preparation of plant extract}

Roots collected from the plants were shade-dried and then separately pulverized to fine powders. The powdered roots $(900 \mathrm{~g})$ were extracted with $80 \%$ ethanol $(2 \times 3 \mathrm{~L})$ under reflux. The ethanol extract of each plant was subjected to rotary evaporation $\left(70 \pm 2{ }^{\circ} \mathrm{C}\right)$ and lyophilized using freeze drier. The extracts were stored in the refrigerator. Required concentrations were prepared immediately before use.

\section{Animals}

Wistar albino rats weighting 180 - 200 g were used. They were obtained from Laboratory Animal Care Unit, College of Pharmacy, Prince Sattam Bin Abdulaziz University, Saudi Arabia. The animals were kept under standard conditions of temperature $\left(22 \pm 1{ }^{\circ} \mathrm{C}\right)$, relative humidity (55 $\pm 5 \%$ ), and $12 \mathrm{~h} / 12 \mathrm{~h}$ light / dark cycle, and fed with standard pellet diet with water provided ad libitum. All experimental procedures followed the guiding principles of the Institute for Laboratory Animal Research (2011) in Guide for the Care and Use of Laboratory Animals [14] and were approved by the Ethical Review Committee (Protocol no. PHARM-3-3-2015), Pharmacy College, Prince Sattam Bin Abdulaziz University, Al-Kharj, KSA.

\section{Acute toxicity studies}

Acute toxicity test was carried out in rats according to OECD - 423 Guidelines [15]. Two groups of Wistar albino rats $(n=6)$ were fasted overnight, and then treated with $A$. gummifera and $A$. kurdicus extracts, respectively at an oral dose of $2000 \mathrm{mg} / \mathrm{kg}$. Control animals received vehicle (3\% v/v Tween 80 in distilled water). Each animal was observed for symptoms of toxicity and/or death every $15 \mathrm{~min}$ in the first $4 \mathrm{~h}$ after treatment, then every $30 \mathrm{~min}$ for successive $6 \mathrm{~h}$ intervals, and then daily for the next $48 \mathrm{~h}$. Since there were no deaths at this dose; the dose of the tested extracts was 
increased to $4 \mathrm{~g} / \mathrm{kg}$ and the rats were monitored for another $48 \mathrm{~h}$.

\section{Justification of dose selection}

A. gummifera and $A$. kurdicus extracts were safe at $4.0 \mathrm{~g} / \mathrm{kg}$ and thus 1/20th and 1/10th (200 and $400 \mathrm{mg} / \mathrm{kg}$, respectively) were chosen for the present investigation.

\section{Anti-inflammatory activity}

Anti-inflammatory effect was evaluated in rats using carrageenan-induced paw edema [16]. Six groups of animals $(n=6)$ were fasted overnight prior to the study, with free access to water. The 1 st and 2nd groups (normal control and reference, respectively) were treated orally with vehicle $(5 \mathrm{~mL} / \mathrm{kg})$ and DEX $(0.2 \mathrm{mg} / \mathrm{kg})$, respectively. A. gummifera extract (at 200 and $400 \mathrm{mg} / \mathrm{kg}$ ) was administered orally to the $3 \mathrm{rd}$ and 4th groups, respectively; while $A$. kurdicus extract was administered orally to the 5th and 6th groups at doses of 200 and $400 \mathrm{mg} / \mathrm{kg}$, respectively. After $30 \mathrm{~min}$, inflammation was induced by sub-plantar injection of $1 \%$ carrageenan $(0.1 \mathrm{~mL})$ in the left hind paw of all animals. The paw volumes up to the tibiotarsal joint were measured in $\mathrm{mL}$ using a plethysmometer (Apelex, France), immediately before and at 1, 2 and $3 \mathrm{~h}$ after carrageenan administration. Mean increases in injected paw volume were measured, and the percentage inhibition of paw edema was calculated using the equation below:

Inhibition $(\%)=\{1-(\mathrm{Vt} / \mathrm{Vc})\} 100$

where $\mathrm{Vt}$ and $\mathrm{Vc}$ are the mean changes in paw volume of treated and control rats, respectively.

\section{Induction of UC in rats}

After $16 \mathrm{~h}$ fast, the rats were lightly anesthetized with pentobarbital sodium ( $30 \mathrm{mg} / \mathrm{kg}$, i.p.), and an $8 \mathrm{~cm}$ polyethylene catheter was introduced into the rectum of each rat. UC was induced in the rats (except the normal control group) by infusing $1 \mathrm{~mL}$ of $4 \%$ acetic acid (in $0.9 \% \mathrm{NaCl}$ ) though the polyethylene catheter. Thereafter, the rats were maintained in a head-down position for $30 \mathrm{~s}$ to limit ejection of the solution. Two days after colitis induction, the animals were euthanized and the distal $8 \mathrm{~cm}$ of the colon was resected for estimation of different parameters.

\section{Experimental design}

Seven groups of rats $(n=6)$ were used. Groups 1 and 2 (normal control and colitis control, respectively) were treated with vehicle $(5 \mathrm{~mL} / \mathrm{kg})$. Group 3 rats (reference) received DEX at 0.2 $\mathrm{mg} / \mathrm{kg}$. Rats in groups 4 and 5 were treated with extract of $A$. gummifera at 200 and $400 \mathrm{mg} / \mathrm{kg}$, respectively, while rats in Groups 6 and 7 were treated with $A$. kurdicus extract at 200 and 400 $\mathrm{mg} / \mathrm{kg}$, respectively. All treatments were given orally via an orogastric cannula, once a day for 5 consecutive days, and the last dose was administered $2 \mathrm{~h}$ before colitis induction.

\section{Macroscopic assessment of ulcerative colitis}

The rats were sacrificed under anesthesia $24 \mathrm{~h}$ after colitis induction [17]. Each rat abdomen was opened to expose the colon. Distal colon, $8 \mathrm{~cm}$ in length and $2 \mathrm{~cm}$ proximal to the anus, was excised, flushed out with cold saline solution, opened longitudinally and imaged. The colon samples were weighted, and wet weight/length ratios were calculated $(\mathrm{g} / \mathrm{cm})$. Macroscopic damage of the colon was assessed by the scoring method: $0=$ normal tissue; $1=$ redness without ulcers or swelling; $2=$ redness and swelling; $3=$ one or two ulcers; $4=$ more than two ulcers or one large ulcer; 5 = mild necrosis; 6 $=$ severe necrosis.

Furthermore, ulcer area was estimated for each colon sample with the aid of a $1-\mathrm{mm}^{2}$ grid. Ulcer index $(U)$ was computed as the sum of ulcer area $\left(\mathrm{Ua}, \mathrm{cm}^{2}\right)$ and macroscopic score (Ms)[18].

\section{Assessment of colonic MPO activity}

The activity of MPO (enzyme marker of neutrophil infiltration) was assayed in colon tissues [19]. Specimens from the distal colon (without ulceration) were kept at $-80{ }^{\circ} \mathrm{C}$ before analysis. Colon samples were weighed then homogenized $(50 \mathrm{mg}$ tissue $/ \mathrm{ml}$ ) in a solution containing hexadecyl trimethyl-ammonium bromide $(0.5 \%)$ dissolved in $10 \mathrm{mM}$ sodium phosphate buffer $(\mathrm{pH}$ 7.4) in an ice bath using homogenizer (IKA Werke $\mathrm{GmbH}$, Germany). Colon homogenates were centrifuged at 20,000 $\mathrm{rpm}$ and $4{ }^{\circ} \mathrm{C}$ for $30 \mathrm{~min}$. An aliquot of the supernatant was allowed to react with tetramethyl benzidine $(1.6 \mathrm{mM})$ and $0.1 \mathrm{mM}$ hydrogen peroxide solution. Change in absorbance was estimated spectrophotometrically at $650 \mathrm{~nm}$. MPO activity was determined as the quantity of enzyme degrading $1 \mu$ mole of peroxide/min at $37{ }^{\circ} \mathrm{C}$ and was expressed in units/mg wet tissue.

\section{Microscopic assessment of UC}

Samples from colon were preserved in $10 \%$ formaldehyde solution for 1 week. They were 
dehydrated in graded ethyl alcohol and embedded in paraffin. Sections of $7 \mu \mathrm{m}$ were deparaffinized with xylene and stained with haematoxylin and eosin (H\&E), and then examined microscopically.

\section{Statistics}

Data are expressed as mean \pm standard error of mean (SEM). Statistical differences between treatment groups were analyzed according to one-way analysis of variance (ANOVA) followed by post hoc Tukey's test. $P<0.05$ was considered statistically significant. Statistical analysis was performed using SPSS program (version 8) software package (SPSS Inc, USA).

\section{RESULTS}

\section{Acute toxicity}

A. gummifera and $A$. kurdicus extracts were well tolerated by the rats. In the $48 \mathrm{~h}$ period of acute toxicity evaluation, rats given single dose of 400 $\mathrm{mg} / \mathrm{kg}$ of $A$. gummifera or $A$. kurdicus extracts, showed no mortality and none of them showed any symptoms of toxicity.

\section{Anti-inflammatory activity}

The control group of rats showed paw volumes of $2.44 \pm 0.19,2.46 \pm 0.20$ and $2.49 \pm 0.22 \mathrm{~mL}$ at 1 , 2 and $3 \mathrm{~h}$, respectively, following carrageenan injection (Table 1). DEX significantly reduced carrageenan-induced paw edema. The mean reduction in paw volume of rats treated with DEX was $44.97 \%$ (Fig. 1). A. gummifera also reduced carrageenan- induced edema, but this effect was significant at $400 \mathrm{mg} / \mathrm{kg}$ dose only. Treatment with 200 and $400 \mathrm{mg} / \mathrm{kg}$ of $A$. kurdicus elicited marked decreases in carrageenan-induced paw edema, at the first $(28.68$ and $32.37 \%$, respectively), second (23.17 and $29.67 \%$, respectively) and third (22.48 and $31.72 \%)$ hours, respectively.

Table 1: Anti-inflammatory effect of DEX and ethanol extracts of $A$. gummifera and $A$. kurdicus in carrageenaninduced rat paw edema.

\begin{tabular}{lccccc}
\hline Group & $\begin{array}{c}\text { Dose } \\
\text { (mg/kg) }\end{array}$ & \multicolumn{4}{c}{ Paw volume $\mathbf{( m L})$} \\
\cline { 3 - 6 } & 0.0 & $\mathbf{0 ~ h}$ & $\mathbf{1 ~ h}$ & $\mathbf{2 ~ h}$ & $\mathbf{3 ~ h}$ \\
\hline Control & 0.2 & $1.97 \pm 0.10$ & $2.44 \pm 0.19$ & $2.46 \pm 0.20$ & $2.49 \pm 0.22$ \\
DEX & 200 & $1.91 \pm 0.11$ & $1.28 \pm 0.12^{*}$ & $1.39 \pm 0.11^{*}$ & $1.37 \pm 0.10^{*}$ \\
A. gummifera & 400 & $1.99 \pm 0.09$ & $1.89 \pm 0.17$ & $1.99 \pm 0.16$ & $2.06 \pm 0.19$ \\
& 200 & $1.98 \pm 0.09$ & $1.67 \pm 0.14^{*}$ & $1.79 \pm 0.14^{*}$ & $1.81 \pm 0.14^{*}$ \\
A. kurdicus & 400 & $1.92 \pm 0.07$ & $1.74 \pm 0.16^{*}$ & $1.89 \pm 0.15^{*}$ & $1.93 \pm 0.12^{*}$ \\
& $1.65 \pm 0.13^{*}$ & $1.73 \pm 0.13^{*}$ & $1.70 \pm 0.11^{*}$ \\
\hline
\end{tabular}

Values represent the mean $\pm \operatorname{SEM}(n=6) ;{ }^{*}$ significantly different from the values of control rats at $p<0.05$

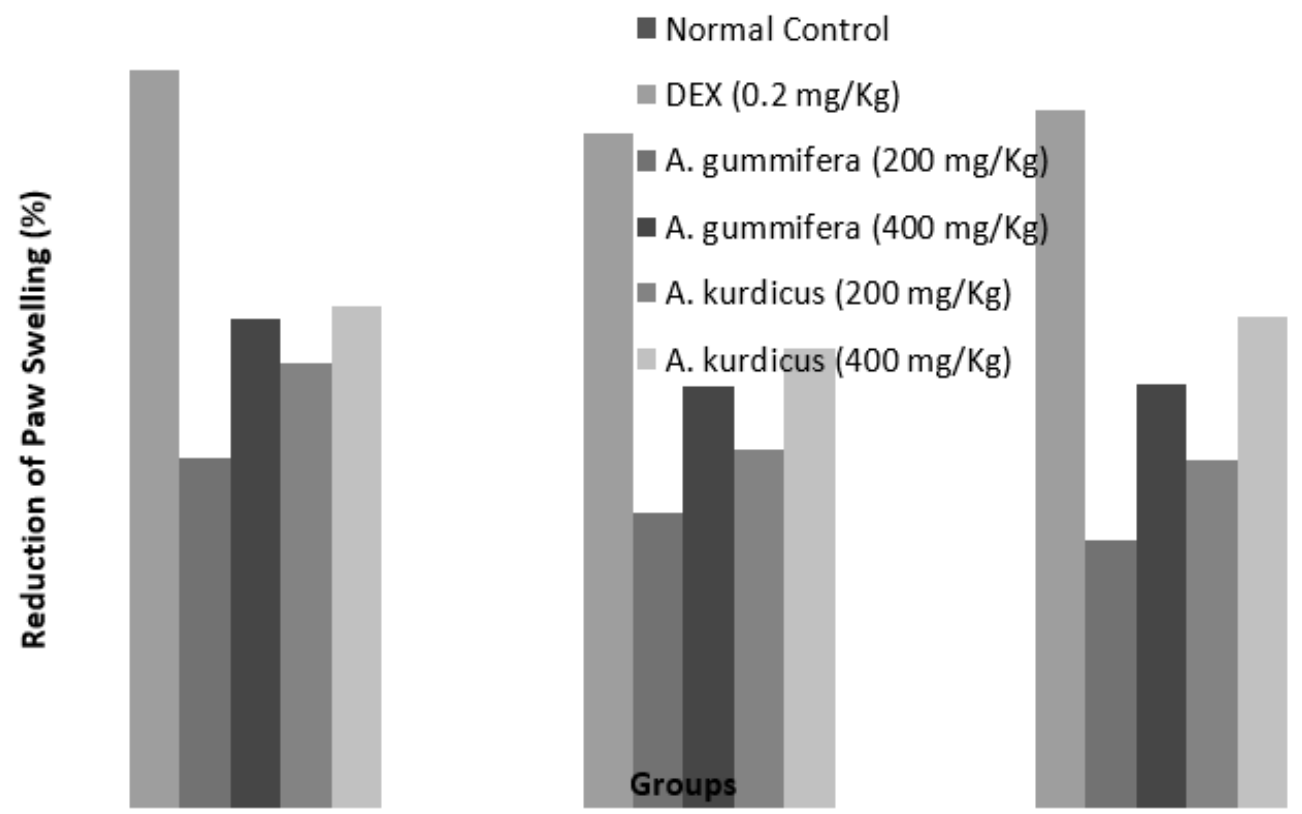

Figure 1: Anti-inflammatory activities of DEX and $A$. gummifera and $A$. kurdicus extracts against carrageenaninduced paw edema in rats 


\section{Macroscopic features of UC}

In this investigation, no abnormal alterations were observed in untreated, normal rats, indicating that handling process did not interfere with the experimental outcomes. After intracolonic administration of acetic acid, the rats with induced colitis showed prostration, pilorection and hypomotility (data not shown). Incidence of diarrhea, as well as colon weight/length lesion score, ulcer area and ulcer index were used as parameters for assessing the protective efficacies of $A$. gummifera and $A$. kurdicus extracts against $U C$ in the rats. In the normal group, diarrhea was absent, while majority of the colitis rats showed marked signs of diarrhea (83.33 \%). DEX, A. gummifera $(400 \mathrm{mg} / \mathrm{kg})$ and A. kurdicus (200 and $400 \mathrm{mg} / \mathrm{kg}$ ) decreased incidence of diarrhea to $33.3,50.0$ and $16.66 \%$, respectively (Table 2 ).

Under dissecting microscope, colonic sections of rats in the control group exhibited typical normal features (Plate 1). On the other hand, colonic sections of the colitis rats appeared ulcerated, oedematous and haemorrhagic (Plate 1B). However, the 5-day pretreatment with DEX and ethanol extracts of $A$. gummifera (at $400 \mathrm{mg} / \mathrm{kg}$ ) and $A$. kurdicus (at 200 and $400 \mathrm{mg} / \mathrm{kg}$ ), significantly decreased the macroscopic lesions produced by the intra-rectal administration of acetic acid (Plate 1C and 1D).

The wet weight/length ratio (an indicator of inflammation) increased more than 3 -fold in colitis rats $(0.94 \pm 0.06 \mathrm{~g} / \mathrm{cm})$ compared to normal control rats $(0.29 \pm 0.02 \mathrm{~g} / \mathrm{cm})$. This ratio was greatly improved in rats pre-medicated with $\operatorname{DEX}(0.33 \pm 0.02 \mathrm{~g} / \mathrm{cm})$, A. gummifera at 400 $\mathrm{mg} / \mathrm{kg}(0.62 \pm 0.04 \mathrm{~g} / \mathrm{cm})$ and $A$. kurdicus at 200

A

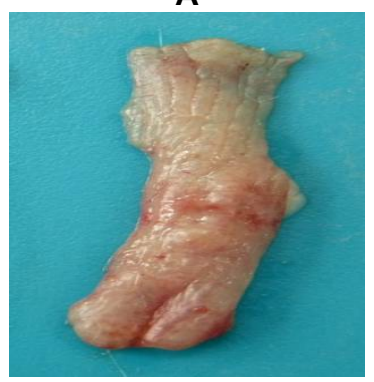

B

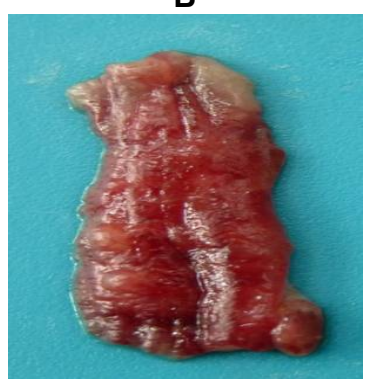

and $400 \mathrm{mg} / \mathrm{kg}(0.71 \pm 0.05$ and $0.54 \pm 0.03$ $\mathrm{g} / \mathrm{cm}$, respectively).Severity of mucosal damage was scored on a 0-6 scale in a randomized, blinded fashion. In the colitis control group, the level of damage was $5.62 \pm 0.37$. Administration of $A$. gummifera $(400 \mathrm{mg} / \mathrm{kg})$ and $A$. kurdicus (200 and $400 \mathrm{mg} / \mathrm{kg}$ ) 5 days before induction of UC significantly decreased inflammatory damage score from $5.62 \pm 0.37$ to $2.60 \pm 0.17,3.13 \pm$ 0.27 and $2.57 \pm 0.15$, respectively (Table 2 ).

Ulcer area $\left(3.10 \pm 0.11 \mathrm{~cm}^{2}\right)$ and ulcer index $(8.72 \pm 0.57)$ values in colitis control rats were significantly increased after intra-rectal infusion of $4 \%$ acetic acid, when compared to normal rats. Pre-treatment with $A$. gummifera (400 $\mathrm{mg} / \mathrm{kg}$ ) and A. kurdicus (200 and $400 \mathrm{mg} / \mathrm{kg}$ ) extracts for 5 days significantly and dose dependently attenuated the increases in ulcer area and ulcer index compared to colitis control rats (Table 2 and Figure 2). The $200 \mathrm{mg} / \mathrm{kg}$ dose of the ethanol extract of $A$. gummifera did not offer protection against the colonic lesions induced by acetic acid.

\section{Colonic MPO activity}

The activity MPO in the colonic tissue was estimated by a standard enzymatic assay. Figure 3 depicts elevated levels of MPO in colonic mucosa of rats following intra-rectal infusion of 4 $\%$ acetic acid compared to normal control group $(16.40 \pm 0.85 \mathrm{U} / \mathrm{g}$ and $4.27 \pm 0.18 \mathrm{U} / \mathrm{g}$, respectively). Pretreatment with either $400 \mathrm{mg} / \mathrm{kg}$ of A. gummifera or 200 and $400 \mathrm{mg} / \mathrm{kg}$ of $A$. kurdicus extracts for 5 days produced significant decreases in MPO activity $(9.33 \pm 0.11,11.70 \pm$ 0.14 and $9.18 \pm 0.10 \mathrm{U} / \mathrm{g}$, respectively) compared to colitis control animals (16.40 \pm $0.85 \mathrm{U} / \mathrm{g})$.
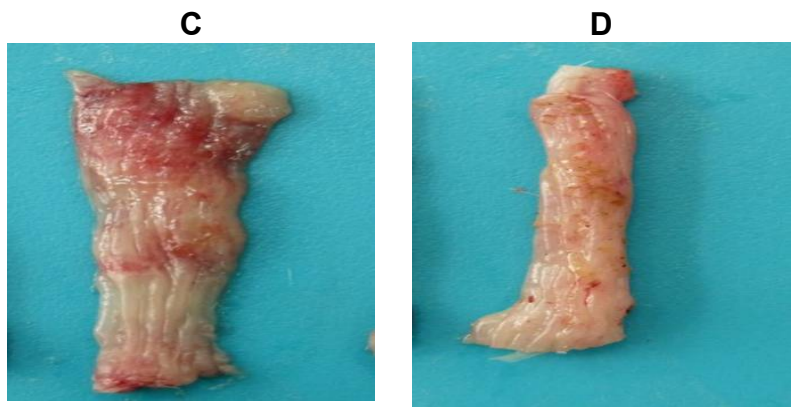

Plate 1: Photographs of colons. (A) Normal control rat. (B) Colitis control rats. Note the extensive hyperemia, edema, and ulceration of the colon. This colon was given a damage score of $5.62 \pm 0.37$. (C and $D$ ) colitis rat administered $400 \mathrm{mg} / \mathrm{kg}$ of $A$. gummifera or $A$. kurdicus extracts, respectively 5 days before the acetic acid challenge. Note the improvement in the level of hyperemia, edema, and ulceration of the colon. These colons were given damage scores of $2.60 \pm 0.17$ and $2.57 \pm 0.15$, respectively 
Table 2: Effects of DEX and ethanol extracts of $A$. gummifera and $A$. kurdicus on the macroscopic parameters of ulcerative colitis induced by acetic acid in rats

\begin{tabular}{|c|c|c|c|c|c|}
\hline Group & $\begin{array}{c}\text { Dose } \\
(\mathrm{mg} / \mathrm{kg})\end{array}$ & $\begin{array}{l}\text { Incidence } \\
\text { of diarrhea }\end{array}$ & $\begin{array}{c}\text { Colon } \\
\text { weight/length } \\
(\mathrm{g} / \mathrm{cm})\end{array}$ & $\begin{array}{c}\text { Macroscopical } \\
\text { score } \\
(0-6)\end{array}$ & $\begin{array}{c}\text { Ulcer area } \\
\left(\mathrm{cm}^{2}\right)\end{array}$ \\
\hline Normal control & 0.0 & $0 / 6(0 \%)$ & $0.29 \pm 0.02$ & $0.00 \pm 0.00$ & $0.0 \pm 0.00$ \\
\hline Colitis control & 0.0 & $\begin{array}{c}5 / 6 \\
(83.33 \%)\end{array}$ & $0.94 \pm 0.06$ & $5.62 \pm 0.37$ & $3.10 \pm 0.11$ \\
\hline DEX & 0.2 & $\begin{array}{c}1 / 6 \\
(16.66 \%)\end{array}$ & $0.33 \pm 0.02^{*}$ & $1.61 \pm 0.15^{*}$ & $0.45 \pm 0.02^{*}$ \\
\hline \multirow[t]{2}{*}{ A. gummifera } & 200 & $\begin{array}{c}4 / 6 \\
(66.66 \%)\end{array}$ & $0.89 \pm 0.04$ & $4.64 \pm 0.30$ & $2.60 \pm 0.21$ \\
\hline & 400 & $\begin{array}{c}2 / 6 \\
(33.33 \%)\end{array}$ & $0.62 \pm 0.04^{*}$ & $2.60 \pm 0.17^{*}$ & $0.87 \pm 0.05^{*}$ \\
\hline \multirow[t]{2}{*}{ A. kurdicus } & 200 & $3 / 6(50.0 \%)$ & $0.71 \pm 0.05^{*}$ & $3.13 \pm 0.27^{*}$ & $1.35 \pm 0.08^{*}$ \\
\hline & 400 & $\begin{array}{c}1 / 6 \\
(16.66 \%)\end{array}$ & $0.54 \pm 0.03^{*}$ & $2.57 \pm 0.15^{*}$ & $0.80 \pm 0.06^{*}$ \\
\hline
\end{tabular}

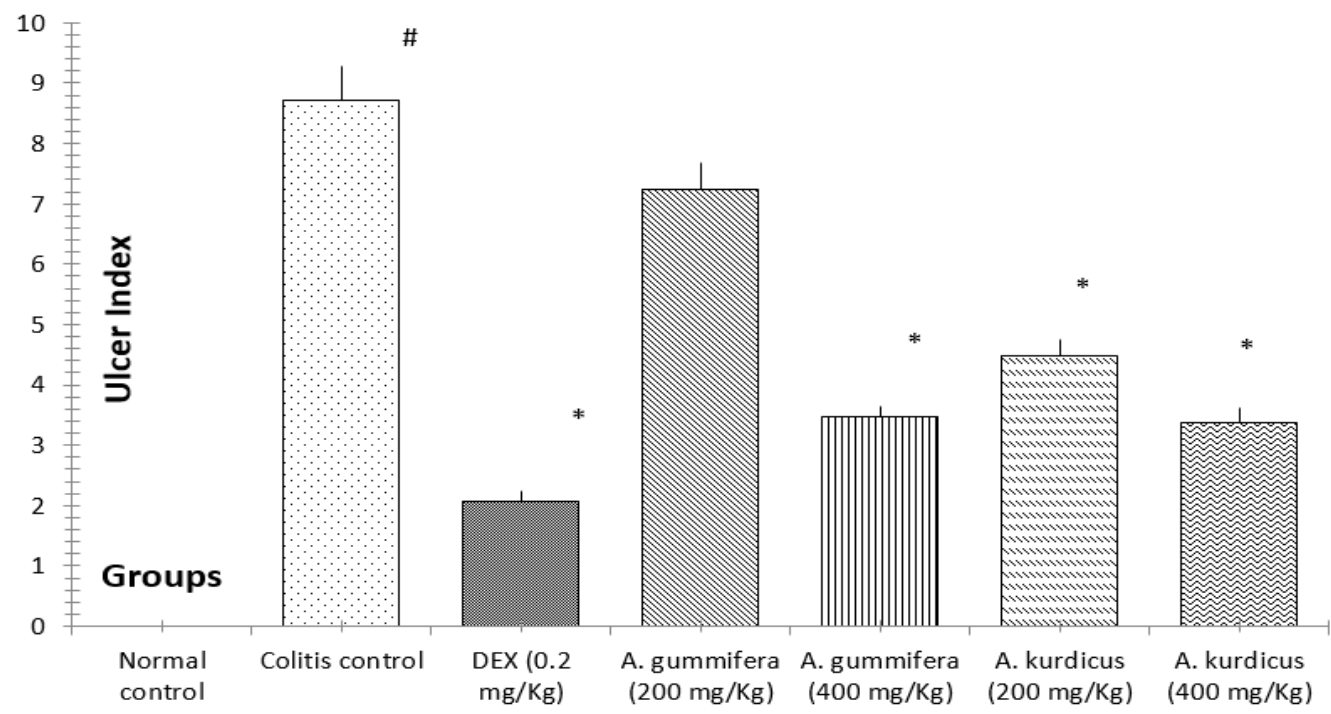

Figure 2: Effects of DEX and A. gummifera and $A$. kurdicus extracts on ulcer index of UC induced by acetic acid in rats. Values represent are mean \pm S.E.M. for six rats for each group. Significantly different from the values of the normal control (\#) and colitis control $\left(^{*}\right)$ rats, at $P<0.05$

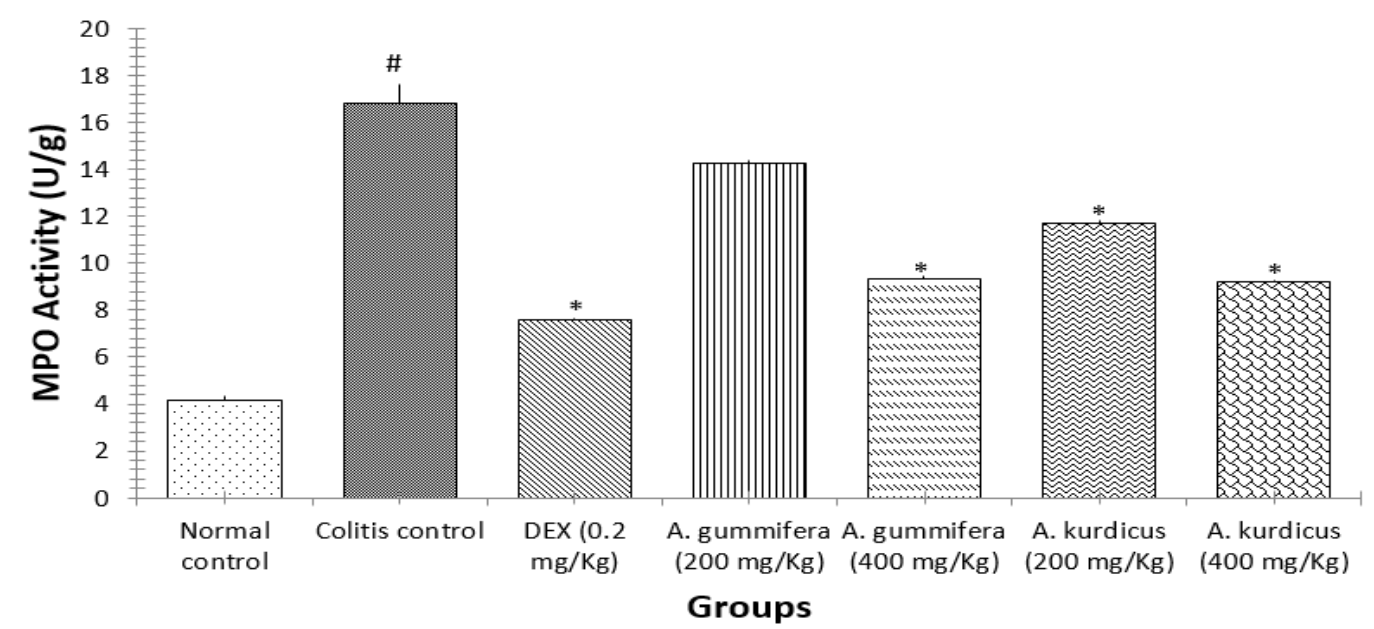

Figure 3: Effects of DEX and A. gummifera and A. kurdicus extracts on MPO activity in UC induced by acetic acid in rats. Values are mean \pm S.E.M. of six rats for each group. ${ }^{\#}$ Significantly different from normal control and colitis control $\left(^{*}\right)$ rats $(P<0.05)$ 
A

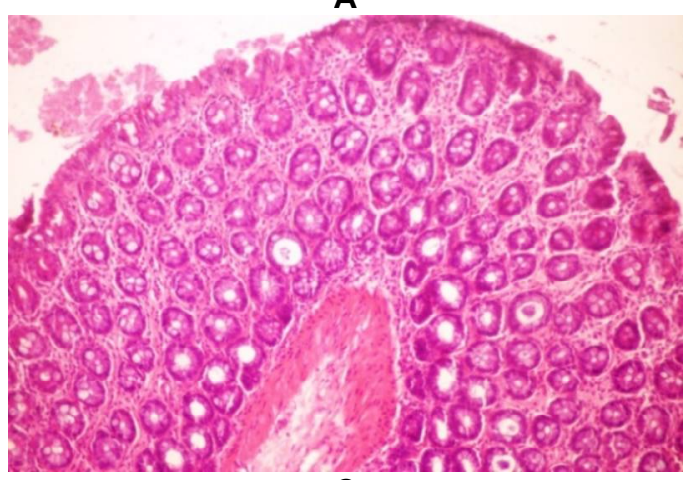

C

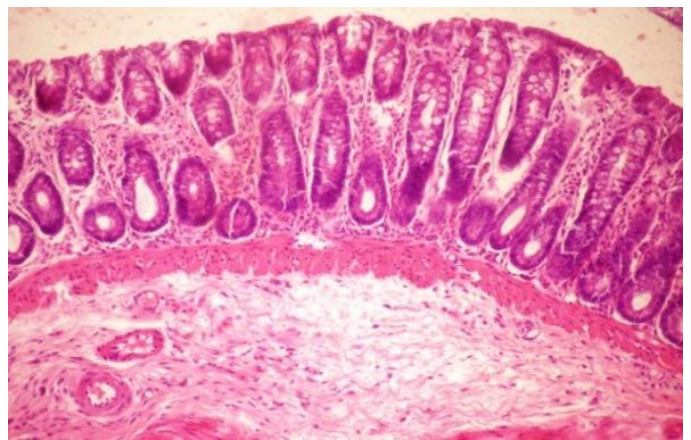

B
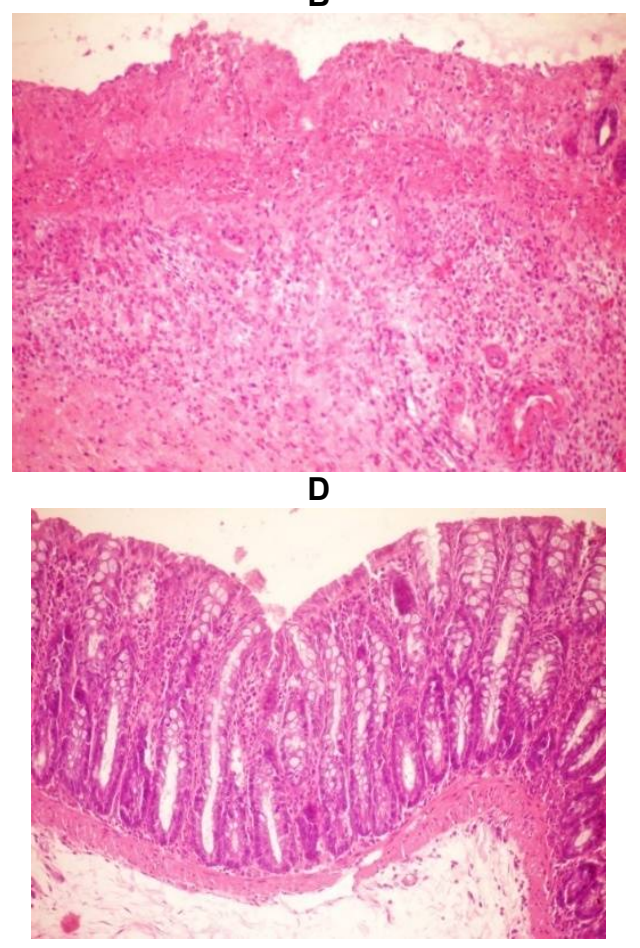

Plate 2: Photomicrographs of haematoxylin and eosin-stained paraffin sections of rat colonic tissues. Control group showing normal features (A), and colitis control group showing massive necrotic destruction of epithelium, sub-mucosal edema, and inflammatory cell infiltration in lamina propria, as well as loss of epithelium integrity (B). Pre-treatment with $400 \mathrm{mg} / \mathrm{kg}$ of $A$. gummifera or $A$. kurdicus extract, attenuated the extent and severity of the histological lesions (C and D) (x 400)

\section{Microscopic features of UC}

The colon mucosa of normal control rats had a typical normal architecture with intact epithelium (Plate 2). In contrast, colon mucosa from the colitis control animals exhibited severe necrotic destruction of epithelium and inflammatory reactions (sub-mucosal edema, ulceration and loss of epithelium integrity as well as inflammatory cell infiltration in lamina propria (Plate 2B). Pretreatment with $A$. gummifera (Plate 2C) or A. kurdicus (Plate 2D) markedly reduced the severity of cellular lesions.

\section{DISCUSSION}

Acute toxicity results revealed the non-toxic nature of $A$. gummifera and $A$. kurdicus extracts. Rats treated with doses up to $4000 \mathrm{mg} / \mathrm{kg}$ of $A$. gummifera and $A$. kurdicus did not exhibit physical symptoms of toxicity throughout the experimental period, and no mortalities were detected. Thus, the $\mathrm{LD}_{50}$ values of these extracts were higher than $4 \mathrm{~g} / \mathrm{kg}$. In general, the higher the $L_{50}$ value, the lower the toxicity of the test compound under investigation. Therefore, the tested extracts can be categorized according to Buck et al, [20] as highly safe since drugs with $\mathrm{LD}_{50}$ values higher than $50 \mathrm{mg} / \mathrm{kg}$ are considered non-toxic. Moreover, drugs with oral $\mathrm{LD}_{50}$ values higher than $4000 \mathrm{mg} / \mathrm{kg}$ are classified as safe or practically non-toxic [21].

In this study, we investigated potential antiinflammatory activities of $A$. gummifera and $A$. kurdicus extracts in a carrageenan model. This model has been accepted as an adequate inflammatory tool for investigating the antiinflammatory effect of extracts and chemical compounds. Injection of $1.0 \% \lambda$-carrageenan induced edema in the foot pad of the rat hind paw. Progression of edema in rat paw as a result of carrageenan injection is a biphasic event [22]. The first phase of edema that lasts for $1 \mathrm{~h}$ is due to the release of serotonin and histamine. The second phase is related to the release of prostaglandins, protease and lysosome. The results of our study indicate that the ceiling volume of foot pad was observed $3 \mathrm{~h}$ following carrageenan-injection. Pretreatment with DEX, $400 \mathrm{mg} / \mathrm{kg}$ of $A$. gummifera and 200 and 400 $\mathrm{mg} / \mathrm{kg}$ of $A$. kurdicus protected against the carrageenan-induced acute inflammation over a period of $3 \mathrm{~h}$. The observed anti-inflammatory effect of both extracts might be due to the presence of flavonoids. It has been suggested that the in vivo anti-inflammatory activity of Astragalus plants may be mediated by inhibition of NF-kappa B activation and mRNA expression [23]. 
Ulcerative colitis induced by rectal infusion of 4 $\%$ acetic acid in rats is a well-established animal model, which is phenotypically similar to human colitis [24]. The mechanism of induction of colitis by acetic acid appears to involve entrance of the protonated form of the acid to the epithelium, where it dissociates to liberate protons, thereby bringing about intracellular acidification which results in massive epithelial damage [25].

Different drugs have been used in the control of UC. However, their side effects pose serious clinical problems. Thus, attention is shifting towards use of naturally-occurring alternative treatments in combination with conventional medication. For this purpose, plants of Astragalus species are valuable due to their antiinflammatory and antimicrobial effects [26].

In this present study, infusion of acetic acid into rat rectum produced a marked increase in the incidence of diarrhea as well as increase in colon weight which were correlated with inflammation and ulceration. Comparable pathological impairments were earlier reported in the same animal model [27]. Pretreatment with DEX, A. gummifera and $A$. kurdicus resulted in marked protection as demonstrated by decreases in acetic acid-induced diarrhea, inflammation and ulceration. Although the exact mechanism by which $A$. gummifera and $A$. kurdicus extracts protected against UC is not fully understood, it could be attributed to their inhibitory effects on the release or synthesis of inflammatory mediators generated by acetic acid. It has been suggested that flavonoids may have beneficial effects in the treatment of disorders associated with oxidative stress, such as inflammatory diseases [28].

The anti-inflammatory effects showed by $A$. gummifera and $A$. kurdicus extracts were also assessed biochemically. Measurement of MPO activity has been used as an index of inflammation in several tissues, including the colon [19]. MPO (a marker of neutrophil activity) is an enzyme found predominantly in neutrophils, which are the main inflammatory cell types that infiltrate injured mucosa during acetic acid exposure [29]. In this study, colonic MPO activity was very low in normal (control) animals but was markedly increased in colitis rats, which is strongly suggestive of massive neutrophil infiltration. Activated neutrophils enter inflamed mucosa of the large intestine during acute inflammation, leading to excess generation of reactive oxygen-derived free radicals and/or proteases such as elastase and collagenase, resulting in intestinal injury [30]. A decrease in the activity of MPO is a manifestation of antiinflammatory activity. In present study, pretreatments with $A$. gummifera $(400 \mathrm{mg} / \mathrm{kg})$ and $A$. kurdicus (200 and $400 \mathrm{mg} / \mathrm{kg}$ ) resulted in attenuation of acetic acid-induced increases in MPO. This indicates a decrease in the neutrophil infiltration of colonic mucosa, since MPO activity is considered a biochemical marker of neutrophil infiltration [19].

\section{CONCLUSION}

The results of present study suggest that ethanol extracts of $A$. gummifera and $A$. kurdicus have protective activities against UC in rats due to their anti-inflammatory properties.

\section{DECLARATIONS}

\section{Acknowledgement}

The authors wish to thank Messrs Abdulrahman A Sharahili and Rashed I Aleselan (graduate student), Department of Pharmacology, College of Pharmacy, Prince Sattam Bin Abdulaziz University, for their gracious assistance in this study.

\section{Conflict of Interest}

No conflict of interest associated with this work.

\section{Contribution of Authors}

The authors declare that this work was done by the authors named in this article and all liabilities pertaining to claims relating to the content of this article will be borne by them.

\section{REFERENCES}

1. Luk $H$, Fung $H$, Cho $C$. Delineation of the protective action of zinc sulfate on ulcerative colitis in rats. Euro $\mathrm{J}$ Pharmacol 2002; 443: 197-204.

2. Chang JC, Cohen RD. Medical management of severe ulcerative colitis. Gastroenterol Clinics of North America 2004; 33: 235-250.

3. Patil MVK, Kandhare AD, Bhise $S D$, Bhale S. A comparative cross sectional descriptive market survey of various brands of Levofloxacin. Asian $J$ Pharm Bio Res 2011; 1: 174-181.

4. AbdKadir SL, Yaakob H, Mohamed Zulkifli R. Potential anti-dengue medicinal plants: A review. J Nat Med 2013; 67:677-689.

5. Davis PH. Flora of Turkey and East Aegean Island, vol. 4. University Press, Edinburgh, 1970: 49-254.

6. Bedir E, Pugh N, Calıs I, Pasco DS, Khan IA. Immunostimulatory effects of cycloartane-type triterpene 
glycosides from Astragalus species. Bio Pharm Bull 2000; 23: 834-837

7. Rios JL, Waterman PG. A review of the pharmacology and toxicology of Astragalus. Phytother Res 1997; 11: 411-418.

8. Pistelli L. Secondary metabolites of genus Astragalus: structure and biological activity. In: Atta-Ur-Rahman (Ed.), Studies in Natural Products Chemistry (Bioactive Natural Products, Part H). Elsevier Science B.V., Karachi, 2002: 443-545.

9. Tang W, Eisenbrand G. Chinese Drugs of Plant Origin. Springer-Verlag, Berlin, 1992: 191-197.

10. Zargari A. Tehran: Tehran University Publications, 6th ed. Medicinal Plants. 1996: 520-521

11. Li X, Qu L, Dong Y, Han L, Liu E, Fang S, Zhang Y, Wang T. A Review of Recent Research Progress on the Astragalus Genus. Molecules 2014; 19: 18850-18880.

12. Shirataki Y, Takao M, Yoshida S, Toda S. Anti-oxidative components isolated from the roots of Astragalus membranaceus Bunge (Astragali Radix). Phytother Res 1997: 11: 603-605.

13. Hou YD, Ma GL, Wu SH, Li YY, Li HT. Effect of Radix AstragaliseuHedysari on the interferon system. Chinese Med J (England) 1981; 94: 35-40.

14. Institute for Laboratory Animal Research: Guide for the Care and Use of Laboratory Animals. Eighth Edition, The National Academies Press, Washington, DC. 2011

15. Organization for Economic Cooperation and Development. The OECD 423 Guideline for Testing of Chemicals Acute Oral Toxicity, Paris, France, 2001.

16. Winter CA, Risley EA, Nuss GW. Carrageenan-induced edema in hind paws of the rat as an assay for antiinflammatory drugs. Proc Society Exp Bio Med 1962; 111:544-547.

17. Kannan N, Guruvayoorappan C. Protective effect of Bauhinia tomentosa on acetic acid induced ulcerative colitis by regulating antioxidant and inflammatory mediators. Int Immunopharmacol 2013; 16: 57-66.

18. Varshosaz J, Emami J, Fassihi A, Tavakoli N, Minaiyan M, Ahmadi F, Mahzouni P, Dorkoosh F. Effectiveness of budesonide-succinate-dextran conjugate as a novel prodrug of budesonide against acetic acid-induced colitis in rats. Int J Colorectal Dis 2010; 25: 1159-1165.
19. Krawisz JE, Sharon P, Stenson WF. Quantitative assay for acute intestinal inflammation based on myeloperoxidase activity. Assessment of inflammation in rats and hamster models, Gastroenterol 1984; 87: 1344 -1350 .

20. Buck W, Osweiter G, Van Gelder A. Clinical and Diagnostic Veterinary Toxicology., 2nd Ed., Kendall/Hunt Publishing Co., lowa, 1976: 380.

21. Kennedy GL, Ferenz RL, Burgess BA. Estimation of acute oral toxicity in rats by determination of the approximate lethal dose rather than the LD50. J Applied Toxicol 1986; 6: 145-148.

22. Gupta M, Mazumder UK, Gomathi P, Thamilselvan V. Anti-inflammatory evaluation of leaves of Plumeria acuminate. BMC Complement Alternat Med [Internet] 2006; 36: 1472-6882.

23. Zhang WJ, Hufnagl $P$, Binder BR, Wojta J. Antiinflammatory activity of astragaloside $I V$ is mediated by inhibition of NF-kappaB activation and adhesion molecule expression. Thrombosis and Haemostasis 2003; 90: 904-914.

24. Hartmann RM, Morgan Martins MI, Tieppo J, Fillmann HS, Marroni NP. Effect of Boswellia serrata on antioxidant status in an experimental model of colitis rats induced by acetic acid. Digest Dis Sci 2012; 57: 2038-2044.

25. Das S, Kanodia L. Effect of ethanolic extract of leaves of Moringa olifera lam. on acetic acid induced colitis in albino rats. Asian J Pharm Clin Res 2012; 5: 110-114.

26. Cakılcıoğlu U, Türkoğlu I. An ethnobotanical survey of medicinal plants in Sivrice (Elazığ- Turkey). J Ethnopharmacol 2010; 132: 165-175.

27. El-Abhar HS, Hammad LN, Gawad HS. Modulating effect of ginger extract on rats with ulcerative colitis. $J$ Ethnopharmacol 2008; 118: 367-372.

28. Rice-Evans C. Flavonoid antioxidants. Current Med Chem 2001; 8: 797-807.

29. Yamada T, Zimmerman BJ, Specian RD, Grisham MB. Role of neutrophils in acetic acid-induced colitis in rats. Inflammation 1991; 15: 399-411.

30. Kruidenier L, Verspaget HW. Oxidative stress as a pathogenic factor in inflammatory bowel diseaseradicals or ridiculous? Aliment Pharmacol Therap 2002; 16: 1997-2015. 